\title{
Cost-effectiveness of pharmacological and psychosocial interventions for schizophrenia
}

Pudtan Phanthunane ${ }^{1,24^{*}+}$, Theo Vos ${ }^{1,2 \dagger}$, Harvey Whiteford ${ }^{2,3}$ and Melanie Bertram ${ }^{1,4}$

\begin{abstract}
Background: Information on cost-effectiveness of interventions to treat schizophrenia can assist health policy decision making, particularly given the lack of health resources in developing countries like Thailand. This study aims to determine the optimal treatment package, including drug and non-drug interventions, for schizophrenia in Thailand.

Methods: A Markov model was used to evaluate the cost-effectiveness of typical antipsychotics, generic risperidone, olanzapine, clozapine and family interventions. Health outcomes were measured in disability adjusted life years. We evaluated intervention benefit by estimating a change in disease severity, taking into account potential side effects. Intervention costs included outpatient treatment costs, hospitalization costs as well as time and travel costs of patients and families. Uncertainty was evaluated using Monte Carlo simulation. A sensitivity analysis of the expected range cost of generic risperidone was undertaken.

Results: Generic risperidone is more cost-effective than typicals if it can be produced for less than 10 baht per 2 mg tablet. Risperidone was the cheapest treatment with higher drug costs offset by lower hospital costs in comparison to typicals. The most cost-effective combination of treatments was a combination of risperidone (dominant intervention). Adding family intervention has an incremental cost-effectiveness ratio of 1,900 baht/DALY with a 100\% probability of a result less than a threshold for very cost-effective interventions of one times GDP or 110,000 baht per DALY. Treating the most severe one third of patients with clozapine instead of risperidone had an incremental cost-effectiveness ratio of 320,000 baht/DALY with just over 50\% probability of a result below three times GDP per capita.

Conclusions: There are good economic arguments to recommend generic risperidone as first line treatment in combination with family intervention. As the uncertainty interval indicates the addition of clozapine may be dominated and there are serious side effects, treating severe patients with clozapine is advisable only for patients who do not respond to risperidone and only in the presence of a stricter side effect monitoring system than currently exists.
\end{abstract}

\section{Background}

Schizophrenia generally begins in early adulthood and causes long term mental and physical impairment [1]. It has a significant impact on individuals, families and countries in terms of both health and economic loss. In the 1999 Thai Burden of Disease and Injury study, schizophrenia was responsible for $5 \%$ of all non-fatal health loss measured in years lived with disability [2]. The

\footnotetext{
* Correspondence: pudtan.phanthunane@uqconnect.edu.au

† Contributed equally

${ }^{1}$ Setting Priorities Using Information on Cost-Effectiveness (SPICE) project,

Ministry of Public Health, Nonthaburi, Thailand

Full list of author information is available at the end of the article
}

direct health care costs of schizophrenia account for between $1 \%$ and $3 \%$ of total national health care expenditure worldwide [3-5]. Indirect costs related to lost productivity are estimated to be higher or at least equivalent to direct costs, in the range of 1 to 7 times the direct costs [3,5-7]. The evidence, however, indicates that Asian countries have a larger proportion of indirect costs (87\% in Taiwan, $83 \%$ in Korea, and $63 \%$ in India) $[5,8,9]$ than those reported in Western countries $(47 \%$ to $70 \%)$ [3].

Thailand has limited health resources for mental disorders, including schizophrenia. The government devoted only $3.0 \%$ of health expenditure to mental

\section{Biomed Central}


health in 2008 [10]. It is therefore paramount that decision makers have access to cost-effectiveness information to prioritise allocation of resources within their budget constraints.

Medications are the standard treatment to control acute psychotic symptoms of schizophrenia. The newer 'atypical' antipsychotics have a similar effect on psychotic symptoms as first-generation 'typical' antipsychotics but cause different side effects and are much more expensive [11-13]. The key problems with using medications alone are poor adherence and a partial improvement in functional outcomes only [14]. A combination of drug and non-drug interventions is commonly recommended [15-17].

To our knowledge, there are no cost-effectiveness studies indicating what should be the first and second line drug treatments in Thailand. This study aims to provide policy makers with evidence on the optimal package of drug and non-drug interventions for schizophrenia. We undertook the current study as part of the Setting Priorities using Information on Cost-Effectiveness (SPICE) project which aimed to provide comparable cost-effectiveness results across various disease areas to assist policy makers in priority setting decision making.

\section{Methods}

We selected interventions for analysis based on: a) efficacy and/or effectiveness in published literature; b) availability of evidence on clinical effectiveness, resource utilization and costs; c) feasibility of implementation in Thailand based on discussions with 10 local mental health experts; and d) relevance to current policy-making. Four drug interventions (typicals, risperidone, olanzapine and clozapine) and family interventions were chosen for analysis. The comparator was a hypothetical 'do nothing' scenario using generalized cost-effectiveness. This required a back-calculation from current practice to the 'partial null', i.e. a hypothetical scenario where we removed the effect of all currently implemented interventions $[18,19]$. An 'intervention pathway' was calculated to determine the most cost-effective mix of interventions.

Our study design was cost-effectiveness analysis using a Markov model with cycles of one year. Patients with schizophrenia in Thailand in the year 2005 were the target population. Each year patients could remain alive with schizophrenia, recover or die from disease-related or other causes (Figure 1). To reflect the chronic course of schizophrenia, costs and effects were assessed until age 80 or death. The annual transition probabilities were based on local and overseas data (See Additional file 1: Transition probability estimates).

The model was analyzed from a government costing perspective. Our survey showed that $75 \%$ of patients

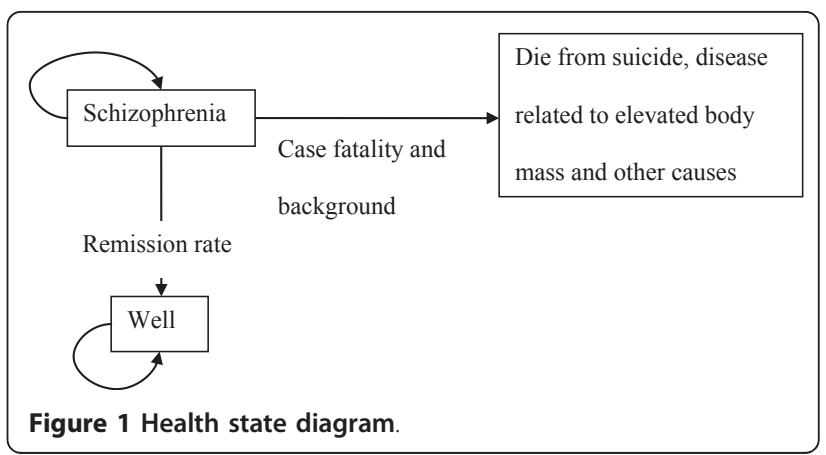

with schizophrenia used the universal coverage health care system [20]. However, because schizophrenia has significant impacts outside the health sector $[1,3]$, we also considered costs to patients and families (time and travel costs). Discounting at 3\% was applied to both costs and benefits to be consistent with the study of Burden of Disease in Thailand and in line with recommendations from the Panel on Cost-Effectiveness in Health and Medicine [2,21]. Our model was constructed using Microsoft Excel.

\section{Health effect estimations}

Health outcomes from the drug and non-drug interventions were measured in disability-adjusted life years (DALYs) averted using identical methods. Intervention effect size was measured as a change in disability weight (DW) using a method described by Magnus et al [22] to translate pooled effect sizes from the international literature into a change in DW. To combine effect sizes, Hedges' g test was applied to determine the mean difference in standard deviation units including an adjustment to correct for small sample sizes [23]. Because the psychiatric literature usually reports efficacy measures based on different psychometric scales [24], we calculated the effect sizes based on the Brief Psychiatric Rating Scale (BPRS) and the Positive and Negative Syndrome Scale (PANSS) in our meta-analyses since they are the most common scales for scoring psychiatric symptoms. Our analyses relied heavily on the information on intervention effects from Cochrane systematic reviews [25-30]. The standardized effect sizes were then pooled using the random effects meta-analysis method to deal with variation around some overall average treatment effect [23]. The method used in the Australian Assessing Cost Effectiveness - Mental Health (ACE$\mathrm{MH})$ project $[22,24]$ to transfer the pooled effect sizes into a change in disability weight was adjusted to include the spread of the Brief Psychiatric Rating ScaleExpanded (BPRS-E) scores from our survey, a cross-sectional descriptive study including 307 people with schizophrenia in Thailand (279 outpatients and 28 inpatients) [20,31]. We mapped each BPRS-E score 
(ranging from $24=$ least severe to $134=$ most severe) to the Dutch lowest and highest DWs for schizophrenia (0.21-0.98) using the methods developed by the ACE$\mathrm{MH}$ Study [24,32]. Note that the lowest disability weight for schizophrenia still means a substantial loss of health reflecting the disability associated with a stigmatized illness as well as some residual symptoms. Across the survey sample we calculated the standard deviation of the BPRS scores and estimated the average health loss (in disability weight) associated with a 1 SD change in severity [20]. As the effect sizes for the impact of interventions are expressed in standard deviation units, we could then impute the average change in disability weight given an effect size for each intervention. The impact of a change in extrapyramidal (EPS) adverse effect was estimated separately and transferred into an additional change in DW. We borrowed data on the proportions of patients with moderate and severe EPS due to typicals (25\%) and atypicals (13\%), as well as the DW of each severity level, i.e. 0.422 and 0.453 for moderate and severe EPS, respectively from the Australian study [22] to calculate the DW change due to less EPS on atypicals. Due to lack of data we had to assume that all the atypicals induced EPS equally.

Apart from accounting for the EPS side effects in the change in DW, we also estimated the mortality and morbidity risks associated with the average weight gain associated with each drug using the potential impact fraction RiskIntegral add-in for Excel (http://www.epigear.com). The benefit of preventing suicide was taken into account for clozapine, the only antipsychotic drug with evidence of this effect [33]. The weighted average relative risk of suicide for people taking clozapine was 0.53, calculated using data from studies by Munro [34] and Harris [35]. Table 1 shows the input parameters used to estimate intervention benefits.

Due to the absence of Thai data on adherence to drug treatment for schizophrenia, we assumed adherence of $47 \%$ («7.4\%) from a review study by Lacro et.al [36]. A study on depression treatment in Thailand found adherence of $41 \%$, indicating a similar level of adherence within the mental health system [37]. We applied this rate for both people receiving atypical and typical antipsychotics $[38,39]$. We provide further details of health effect estimation via the online document (See Additional file 1: Health effect estimations)

\section{Cost estimations}

The cost analyses comprise of: a) intervention cost; b) medical costs for treating or preventing side effects; c) cost of hospitalization; and d) time and travel cost of patients and families. All costs were adjusted to 2005 using the Consumer Price Index (CPI) based on data from the Bank of Thailand website (http://www.bot.or.th).

We estimated the annual drug cost for each of the antipsychotics by combining the unit cost for a standard daily dose with the costs of drug administration (i.e. outpatient visits). Costs of benzhexol, an anticholinergic drug that treats EPS side effects were also included. We separately measured costs of regular blood tests to prevent the fatal adverse effect of clozapine, agranulocytosis [40]. We used a $27 \%$ hospitalization rate among patients on typicals based on local data [20] while adopting the relative reduction in hospitalization rates in patients taking atypicals from Leucht et al. [41]. According to the Cochrane review study, we assumed that by comparison with no treatment typicals reduce the hospitalization rate by $50 \%$ [42].

The costs of family interventions mainly consisted of start-up costs (development and training) and ongoing costs (services, supplies, travel and salary). We assumed that the family intervention protocol would be prepared by 2 specialists employed by the project for 100 hours each and a training program would be conducted for a group of clinicians from all 17 psychiatric hospital across Thailand. One psychiatrist and 20 psychiatric nurses from each hospital would be trained. The family intervention program would consist of 10 weekly 2 -hr sessions by a psychiatric nurse [43]. We assumed that each session would have 16 participants ( 8 patients and 8 family carers). As there is no information on the longer term outcomes of family interventions, we assumed after expert consultation that 2 booster sessions to patients and families every year, would enable

Table 1 Input parameters for estimation of health outcome for drug and non-drug interventions compared to 'do nothing'

\begin{tabular}{|c|c|c|c|c|}
\hline Intervention & DW change $(95 \% \mathrm{CI})$ & RR of suicide & Weight change (kg) & proportion of patients with moderate and high EPS \\
\hline Typicals & $-0.069(-0.032,-0.101)$ & 1 & 1.42 & $25 \%$ \\
\hline Risperidone & $-0.085(-0.050,-0.116)$ & 1 & 2.10 & $13 \%$ \\
\hline Olanzapine & $-0.095(-0.060,-0.127)$ & 1 & 4.15 & $13 \%$ \\
\hline Clozapine & $-0.099(-0.067,-0.128)$ & 0.54 & 4.45 & $13 \%$ \\
\hline Family intervention ${ }^{1}$ & $-0.076(-0.064,-0.085)$ & 1 & - & - \\
\hline
\end{tabular}

Data source: RR of suicide [34,35]; Weight change [56] and Proportion of patients with moderate and high EPS [22,57]

${ }^{1}$ Additional benefit to drug interventions 
the benefit of FI to be maintained over a patient's lifetime.

Time cost was assumed to be $25 \%$ of personal income per capita in Thailand in 2005 (http://www.nesdb.go.th) and travel costs of patient and families were computed using patient-reported data from our survey [20]. The cost parameters, values and data sources are described in the online supporting document (See Additional file 1: Assessment of intervention cost).

\section{Sensitivity analysis}

One way sensitivity analysis was undertaken for (a) intervention costs including and excluding time and travel costs of patients and families; and (b) varying costs of risperidone. Generic risperidone is not yet available in Thailand. However, the Royal College of Psychiatrists of Thailand has urged the Government Pharmaceutical Organization to produce a generic version of risperidone following the expiration of its patent and it is currently in the process of Food and Drug Administration approval [44]. In this sensitivity analysis we modelled risperidone prices ranging from 4 baht (expected generic price [44]) to 50 baht. We compared risperidone to typicals in this sensitivity analysis.

Probabilistic sensitivity analysis using Monte Carlo simulation was undertaken using an Excel add-in Ersatz (http://www.epigear.com). The uncertainties in all values were considered simultaneously using appropriate distributions and relevant parameters. Additional online information provides the details of input parameters, distributions and data sources used for uncertainty analysis (See Additional file 1: Uncertainty parameters and distributions.

\section{Additional policy-relevant criteria}

While the initial results were based on cost-effectiveness analysis, broader aspects which may be important in terms of policy, known as "second filter" criteria, were also considered. In Australian 'Assessing Cost-Effectiveness' studies 'strength of evidence', 'equity', 'feasibility', 'acceptability' and sustainability have been considered [45]. Our expert advisory group and the steering committee of the SPICE project played an important role in applying these second filter criteria and formulating policy recommendations.

\section{Results}

Atypical antyipsychotics were not significantly more effective than typicals in reducing the severity of disease (Tables 1 and 2). Clozapine had an additional benefit of preventing suicide but greater health loss from weight gain than the other drugs (Table 2). Family intervention had additional health benefits when combined with drug treatment.

At a cost of 4 baht per $2 \mathrm{mg}$ tablet, generic risperidone would be the preferred drug treatment due to lower hospital costs despite higher drug costs (Table 3 ). While all atypicals have lower hospital costs than typicals, the drug cost of risperidone, only, was offset by hospital saving. The annual cost of clozapine treatment per individual was about twice that for typicals or risperidone, mostly because of the higher cost of monitoring side effects and the associated time costs of patients. Olanzapine was the most costly drug, approximately 7 times higher than typicals and risperidone. Giving risperidone with family interventions was more expensive than risperidone alone by 4,000 baht in the first year due to higher patient and family costs.

By comparison with 'do nothing', most of the selected interventions, with the exception of clozapine and olanzapine, were cost-saving (Table 4). The cost-effectiveness ratio of clozapine (12,000 baht/DALY averted) was below Thailand GDP per capita of 110,000 baht which is considered the threshold for very cost-effective health interventions (http://www.dcp2.org). When we included costs of patient and family time in the analyses, all of the interventions were no longer dominant but their cost-effectiveness ratios (except for clozapine and olanzapine) still fell well below the threshold of 110,000 baht. Olanzapine (1,000,000 baht/DALY averted) has an unfavourable cost-effectiveness ratio due to its high cost for at most only a small additional benefit over other drug treatments.

Table 2 Health effects of typical and atypical antipsychotic compared to 'do nothing' over the lifetime people with schizophrenia in the 2005 Thai population

\begin{tabular}{|c|c|c|c|c|}
\hline \multirow[t]{2}{*}{ Intervention } & \multicolumn{4}{|c|}{ DALYs averted } \\
\hline & Severity of disease & Weight gain & Mortality due to suicide & Total $(95 \% \mathrm{Cl})$ \\
\hline Typicals & 450,000 & $-5,800$ & - & $440,000(290,000,610,000)$ \\
\hline Risperidone & 540,000 & $-9,100$ & - & $530,000(370,000,710,000)$ \\
\hline Olanzapine & 580,000 & $-14,000$ & - & $570,000(390,000,770,000)$ \\
\hline Clozapine & 620,000 & $-15,000$ & 20,000 & $630,000(440,000,830,000)$ \\
\hline $\mathrm{Fl}+$ Risperidone ${ }^{1}$ & 920,000 & $-9,100$ & - & $910,000(640,000,1,100,000)$ \\
\hline
\end{tabular}

${ }^{1} \mathrm{Fl}=$ family intervention; results are for risperidone together with $\mathrm{Fl}$. 
Table 3 Costs of interventions analyzed per individual receiving the intervention in the first year

\begin{tabular}{|c|c|c|c|c|c|}
\hline \multirow[b]{2}{*}{ Drug intervention } & \multicolumn{4}{|c|}{ Cost (baht/year) } & \multirow[b]{2}{*}{ Total $(95 \% \mathrm{Cl})$} \\
\hline & Intervention & Side effects & Hospitalization & Time cost & \\
\hline Typicals & 3,300 & 400 & 8,100 & 1,300 & $13,000(11,000,15,000)$ \\
\hline Risperidone & 4,300 & 250 & 5,200 & 1,300 & $11,000(9,500,13,000)$ \\
\hline Olanzapine & 81,000 & 160 & 5,200 & 1,300 & $88,000(84,000,93,000)$ \\
\hline Clozapine $^{1}$ & 4,600 & 3,800 & 5,200 & 6,900 & $21,000(19,000,22,000)$ \\
\hline$\overline{F l^{2}+\text { Risperidone }}$ & 6,300 & - & 4,500 & 4,400 & $15,000(13,000,17,000)$ \\
\hline
\end{tabular}

The ideal intervention package would start with generic risperidone, assuming the cost is 4 baht per $2 \mathrm{mg}$ tablet (Figure 2 and Table 5). The next step would be to add family interventions to risperidone with significant health gain at a small net cost (ICER 1,900 baht/DALY; 95\%CI: "dominant", 18,000; 100\% probability of a result below the one times GDP per capita). Providing clozapine instead of risperidone to the most severe one-third of patients has an ICER of 320,000 baht/DALY (95\% CI: 26,000 , "dominated"; $51 \%$ probability of a result below the three times GDP per capita threshold of 330,000 baht/DALY for cost-effective interventions). We assumed that patients who had a score greater than 40 on the BPRS (this would include about one-third of patients in our survey) would be eligible for clozapine $[20,31]$. "Dominated" denotes an intervention more costly and less effective than the comparator, while "dominant" means the intervention is more effective and less costly than the comparator.

Analysis of generic risperidone was based on an "expected cost". The actual cost for generic risperidone could have a significant impact on the cost-effectiveness, so we examined potential values in a one-way sensitivity analysis (Figure 3). If generic risperidone costs less than 10 baht per $2 \mathrm{mg}$ tablet, it is dominant over typicals. Up to a cost of 19 baht ( $95 \%$ uncertainty interval $15-25$ baht) replacing typicals by risperidone would still be considered a very cost-effective intervention against a threshold of 110,000 baht.

Based on the CEA results, the recommended intervention package would be the combination between risperidone, clozapine and family interventions. Providing clozapine for highly severe patients cannot be recommended until it is ensured that its serious side effect of agranulocytosis is prevented: patients receive periodic blood test during this treatment (Table 6).

\section{Discussion}

The three main findings from this study are (a) generic risperidone should be used as the first line drug treatment for schizophrenia if the cost is less than 10 baht per $2 \mathrm{mg}$ tablet; (b) combining risperidone with family interventions will substantially increase health gain with lower hospitalization cost; and (c) clozapine could be a second line medication for patients with high severity who fail to respond to risperidone.

The key recommendation of this study is that risperidone should be included in the national drug list while olanzapine should not (Table 6). Clozapine should be reserved for severe patients who do not

Table 4 Average cost-effectiveness ratios of interventions

\begin{tabular}{|c|c|c|c|c|}
\hline \multirow[t]{2}{*}{ Intervention } & \multicolumn{4}{|c|}{ Average cost-effectiveness ratio } \\
\hline & $\mathrm{Tx}^{1}$ & $\mathrm{Tx}+\mathrm{Hosp}^{2}$ & Tx+Time ${ }^{3}$ & Total \\
\hline Typical & 64,000 & Dominant $^{4}$ & 87,000 & Dominant \\
\hline Risperidone & 66,000 & Dominant & 85,000 & Dominant \\
\hline Olanzapine & $1,100,000$ & 980,000 & $1,100,000$ & $\begin{array}{r}1,000,000 \\
(730,000 ; 1,400,000)\end{array}$ \\
\hline Clozapine & 80,000 & Dominant & 130,000 & 12,000 (Dominant; 38,000) \\
\hline $\mathrm{Fl}^{5}+$ Risperidone & 42,000 & Dominant & 57,000 & Dominant \\
\hline Risperidone $(2 / 3)$ \& Clozapine $(1 / 3)^{6}+\mathrm{Fl}$ & 45,000 & Dominant & 67,000 & Dominant \\
\hline
\end{tabular}

${ }^{1} \mathrm{Tx}=$ average cost-effectiveness ratio taking into account treatment costs only

${ }^{2} \mathrm{Tx}+$ Hosp $=$ average cost-effectiveness ratio taking into account treatment and hospital costs

${ }^{3} \mathrm{Tx}+\mathrm{Time}=$ average cost-effectiveness ratio taking into account treatment and time and travel costs

${ }^{4}$ Dominant $=$ more effective and less costly than comparator $\backslash$

${ }^{5} \mathrm{FI}=$ family intervention

${ }^{6}$ Giving clozapine to one-third of patients with high severity 


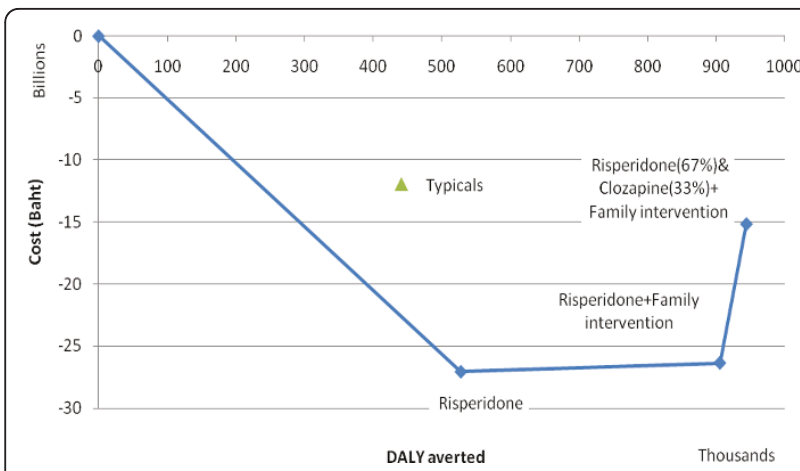

Figure 2 Ideal mix of schizophrenia interventions based on their cost-effectiveness ratio in Thailand.

respond to risperidone as it may have superior benefits in treatment-resistant schizophrenia and in preventing suicidal behaviour $[33,46]$. However, the poor compliance with the Clozapine Patient Monitoring Service program in Thailand [47] means that clozapine cannot be recommended until monitoring has improved.

The stigma of schizophrenia could be a significant barrier to family interventions [48]. More importantly, due to a lack of mental health resources and high travel costs, poor households and people living in rural areas may have limited access. A new stream of long term government funding would be required to provide family interventions across the country and make these services accessible long-term.

This study has several limitations. First, the studies included in our meta-analyses were generally from Western countries not Thailand or other Asian countries. Second, the course of disease varies considerably between patients. Modelling the average cost and impact on the average case of disease could lead to erroneous conclusions [49]. The alternative is to use a microsimulation approach; however, that would require more clinical and epidemiological information on individuals than we had available. Third, the methods used for translating the effect sizes into a change in DW need the assumption that the effect sizes from trials can be directly applied to general health status estimated using a generic measurement. Normally, generic measurements are less relevant to schizophrenia's symptoms by comparison with specific ones as BPRS used in this study. However, this is the only method

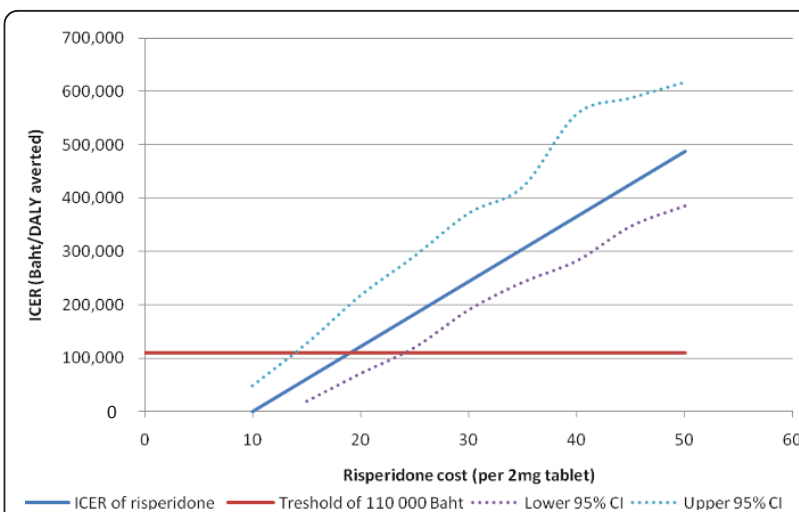

Figure 3 Incremental cost effectiveness analysis results using the range of risperidone costs by comparison with typicals.

allowing us to clarify DWs in patients with different treatments. An advantage of using this method is that we could include Thai data on the individual patients into the analysis. We would content that it is not necessarily so that departure from the assumed linear relationship between symptom change and disability change would lead to over-estimation of health benefits in DALYs. Fourth, the assumption that patients remain on the same treatment throughout the course of their illness is in contrast to the common clinical practice of switching patients from one treatment to another treatment based on individual medication responses [50]. However, a large double-blinded randomized clinical trial in the US suggested no difference in rates of improvement between patients with atypical antipsychotics switching to a new medication and patients staying on their initial treatment [51]. Finally, we have not incorporated the costs of treating diseases related to increased body weight due to unavailability of local disease costing data. Because there is only a small difference in weight gain between typicals and risperidone, this limitation is unlikely to affect the findings.

Our study also has several major strengths. First, the information used for assessing costs and effectiveness of each intervention is documented and transparent, and from Thai sources wherever possible. Second, to our knowledge, there is no previous study including time and travel costs in the cost estimations. Our findings show that these are a significant burden on patients and

Table 5 Incremental cost-effectiveness ratios of optimal package of interventions

\begin{tabular}{|c|c|c|c|}
\hline \multirow[t]{2}{*}{ Intervention(s) } & \multirow[t]{2}{*}{ Incremental cost-effectiveness ratio } & \multicolumn{2}{|c|}{ Probability of ICER below } \\
\hline & & $1 \times \mathrm{GDP}$ & $3 \times$ GDP \\
\hline Risperidone & Dominant & $100 \%$ & $100 \%$ \\
\hline Add Family intervention & 1,900 & $100 \%$ & $100 \%$ \\
\hline Add clozapine to most severe one third replacing risperidone & 320,000 & $38 \%$ & $51 \%$ \\
\hline
\end{tabular}


Table 6 Considerations of additional policy-relevant criteria

\begin{tabular}{|c|c|}
\hline Criteria & schizophrenia \\
\hline & $\begin{array}{c}\text {-We have relied heavily on evidence provided in Cochrane systematic reviews and used their inclusion criteria when adding more } \\
\text { recent trials. } \\
\text { - There is sufficient data for drug interventions while few trials are available for psychosocial intervention. Most trials were } \\
\text { conducted in Western countries and doubts remain about the applicability of these findings to Thailand. A number of further } \\
\text { methodological problems were identified in this trial literature: the varying choice of comparator in the evaluation of psychosocial } \\
\text { interventions; use of high doses of typicals as comparator in trials of newer generation drugs; potential publication bias; and short } \\
\text { durations of follow-up }\end{array}$ \\
\hline Equity: & $\begin{array}{r}\text { - Generic risperidone is recommended as the first line drug treatment and should be included in the national essential drug list so } \\
\text { that it can be prescribed equitably to all Thai patients. } \\
\text { - Lack of mental health resources and higher travel costs for patients and families may make family interventions less available or } \\
\text { affordable in rural and remote areas. Poor households may have less access to this intervention. }\end{array}$ \\
\hline Feasi & $\begin{array}{l}\text { - Increased prescribing of clozapine in Thailand would be advisable only if health care units can maintain monthly blood testing. } \\
\text { This would require additional support from the government to help patients and families with the travel cost. } \\
\text { - The availability of mental health resources psychiatric nurses or psychologists, training programs and accessibility of health care } \\
\text { units are of concern. } \\
\text { - Maintaining the benefit of family interventions annually is possibly more difficult than doing it in the first year for a number of } \\
\text { reasons: (a) the patients migrate to other areas; (b) the families have no time available during the program period; (c) lack of long } \\
\text { term budget to support the program; and (d) the trained nurses change workplace or quit the careers. }\end{array}$ \\
\hline $\mathrm{Acc}$ & $\begin{array}{c}\text { - The major effectiveness measurement of this study is symptom reduction based on clinical perspectives. In fact, the patient and } \\
\text { families might have different views. This measurement by clinicians may be too limited from the point of view of patients and } \\
\text { families who are interested in general wellbeing and productivity gains, for example. However, recent studies [58-60] found that } \\
\text { psychiatric symptoms are the best independent predictors of these broader outcomes of schizophrenia (e.g. objective and } \\
\text { subjective quality of life and social skill functions). } \\
\text { - Some policy makers and clinicians may be reluctant to use clozapine due to its rare but fatal side effect. Although a recent long- } \\
\text { term follow-up study in Finland found a lower mortality rate among people with clozapine than those with other antipsychotics } \\
\text { [61], less intensive monitoring for those on clozapine treatment in Thailand than Finland means these low mortality rates are } \\
\text { unlikely to be achieved [47,61]. } \\
\text { - Self-stigma of people with schizophrenia and their families could be an obstacle to involvement in a psychosocial intervention } \\
\text { program [48]. }\end{array}$ \\
\hline . & In order to maintain lifetime benefits due to family interventions, a long-term public funding is required from the government. \\
\hline
\end{tabular}

families, particularly for clozapine and family interventions. Third, we clearly address the issue of uncertainty in the data, presenting our results as a range within which the value is expected to fall. Fourth, we have had regular contact with local policy makers over the fiveyear span of our work. As a result of this, the food and drug administration in Thailand has already allocated 40 million baht to add generic risperidone to the national essential drug list.

This is the first study of its kind in Thailand. Studies elsewhere have modeled cost-effectiveness of different atypical antipsychotics, with fewer studies addressing both drug and non-drug interventions. Our results are in line with previous research. A study conducted in Slovenia which measured effectiveness as the percentage of patients in remission found that risperidone was more cost-effective than haloperidone and olanzapine for schizophrenia [52]. Studies in Canada, Brazil and Australia consistently found that using risperidone rather than olanzapine would reduce the medical costs of schizophrenia $[22,53,54]$. In contrast, a number of studies using the method developed by the WHOCHOICE project suggested using typical antipsychotics in combination with psychosocial interventions [55]. However, the authors discussed that if generic forms of atypical medication would become available, the findings could change [55] as our sensitivity analysis indicates. Costs associated with drug treatments are a major driver of the results of cost-effectiveness analysis and limit the applicability of our conclusions to other countries.

A combination of psychosocial interventions and medications has been highly recommended as a successful treatment package for schizophrenia [16]. Our results confirm that this package not only provides more health gain to patients, but also could help the government to reduce hospitalization cost by as much as $40 \%$ compared to typicals (Table 3 ). The hospitalization cost is generally considered to be the most expensive component of direct costs $[3,5,8,9]$.

\section{Conclusions}

The cost of medications is the most important factor in the cost-effectiveness of antipsychotic interventions for schizophrenia. Atypicals are more cost-effective than typicals if their generic versions can be produced at a cost level achieved for many other generic medications in Thailand. Family intervention is an additional costeffective option to help not only improve disease severity, but also reduce hospitalizations thus lessening the economic burden on the government. 


\section{Additional material}

Additional file 1: Estimations of transition probabilities, health outcomes and intervention costs. 1) Transition probability

estimates - This file explains a Markov cohort model with 3 health states: alive with schizophrenia, alive without schizophrenia and dead due to suicide, increased body weight or other causes. 2) Health effect estimations - This file describes measurement of the health benefit as a change in severity of disease calculated as a change in disability weight. Additionally, it provides details on estimation of the mortality and morbidity risks associated with weight gain. 3) Uncertainty parameters and distributions - This file gives information on uncertainty parameters, distributions used and data sources. 4) Assessment of intervention cost - This file gives details on cost estimates including cost elements, cost value and data sources.

\section{Acknowledgements}

We would like to acknowledge the Department of Mental Health, Thailand We also would like to thank Dr. Supasit Pannarunothai, Dr. Manit Srisurapanont, Dr. Stephen Lim and Dr. Jan Barendreg for their advice and support. This study was supported by the Setting Priority using information on cost-effectiveness (SPICE), funded by the Wellcome Trust, U.K. (Grant number: 071842/Z/03/Z) and the National Health and Medical Research Council of Australia (Grant number: 301199).

\section{Author details}

${ }^{1}$ Setting Priorities Using Information on Cost-Effectiveness (SPICE) project, Ministry of Public Health, Nonthaburi, Thailand. ${ }^{2}$ School of Population Health, the University of Queensland, Herston, QLD Australia. ${ }^{3}$ Queensland Centre for Mental Health Research, The Park Centre for Mental Health, Summer Park, QLD Australia. ${ }^{4}$ Faculty of Management and Information Sciences, Naresuan University, Phitsanulok, Thailand.

\section{Authors' contributions}

PP, TV and HW participated in the study design and data collection. PP, TV and $\mathrm{MB}$ conducted the data analysis and contributed to design of the modelling strategy. PP wrote the first draft of the manuscript. All authors have been involved in reviewing the manuscript and have given final approval of this manuscript version

\section{Competing interests}

The authors declare that they have no competing interests.

Received: 8 July 2010 Accepted: 13 May 2011 Published: 13 May 2011

\section{References}

1. Barbato A: Schizophrenia and public health Geneva: World Health Organization; 1998

2. Bundhamcharoen $\mathrm{K}$, Teerawatananon $\mathrm{Y}$, Vos T, Begg S: Burden of disease and injuries in Thailand: priority setting for policy Nonthaburi: Ministry of Public Health; 2002.

3. Knapp M, Mangalore R, Simon J: The global costs of schizophrenia. Schizophr Bull 2004, 30:279-293.

4. Lang H-C, Su T-P: The Cost of Schizophrenia Treatment in Taiwan Psychiatr Serv 2004, 55:928-930.

5. Chang SM, Cho S-J, Jeon HJ, Hahm B-J, Lee HJ, Park J-I, Cho MJ: Economic burden of schizophrenia in South Korea. Korean Med Sci 2008, 23:167-175.

6. Kessler RC, Frank RG: The impact of psychiatric disorder on work loss days. Psychol Med 1997, 27:861-873.

7. Lang HC, Su TP: The cost of schizophrenia treatment in Taiwan. Psychiatr Serv 2004, 55:928-930.

8. Lee IH, Chen PS, Yang YK, Liao YC, Lee YD, Yeh TL, Yeh LL, Cheng SH, Chu CL: The functionality and economic costs of outpatients with schizophrenia in Taiwan. Psychiatry Res 2008, 158:306-315.

9. Grover S, Avasth A, Chakrabart S, Bhansali A, Kulhara P: Cost of care of schizophrenia: a study of Indian out-patient attenders. Acta psychiatr Scand 2005, 112:55-63.
10. The Department of Mental Health MoPH: Annual report Bkk: Department of Mental Health; 2008.

11. Pharmacoeconomic modelling in schizophrenia: trap or support for decision makers. [http://www.rees-france.com/en/article.php3? id_article $=470]$.

12. Leucht S, Corves C, Arbter D, Engel RR, Li C, Davis JM: Second-generation versus first-generation antipsychotic drugs for schizophrenia: a metaanalysis. The Lancet 2009, 373:31-41.

13. Kongsakon R, Leelahanaj T, Price N, Birinyi-Strachan L, Davey P: Cost analysis of the treatment of schizophrenia in Thailand: A simulation model comparing olanzapine, risperidone, quetiapine, ziprasidone and haloperidone. J Med Assoc Thai 2005, 88:1267-1277.

14. Martin JLR, Perez V, Sacristan M, Rodriguez-Artalejo F, Martinez C, Alvarez E: Meta-analysis of drop-out rates in randomised clinical trials, comparing typical and atypical antipsychotics in the treatment of schizophrenia. European Psychiatry 2006, 21:11.

15. Mari JdJ, Razzouk D, Thara R, Eaton J, Thornicroft G: Packages of care for schizophrenia in low- and middle-income countries. PLoS Med 2009, 6:1-8.

16. Patterson TL, Leeuwenkamp OR: Adjunctive psychosocial therapies for the treatment of schizophrenia. Schizophr Res 2008, 100:108-119.

17. Taylor $T$, Killaspy H, Wright C, Turton P, White $S$, Kallert T, Schuster M, Cervilla J, Brangier P, Raboch J, et al: A systematic review of the international published literature relating to quality of institutional care for people with longer term mental health problems. BMC Psychiatry 2009, 9:55.

18. Tan-Torres Edejer T, Baltussen R, Adam T, Hutubessy R, Acharya A, Evans D, Murray C: Making choices in health: WHO guide to cost-effectiveness analysis Geneva: World Health Organization; 2003.

19. Chisholm D: Choosing cost-effective interventions in psychiatry: results from the CHOICE programme of the World Health Organization. World Psychiatry 2005, 4:37-44.

20. Phanthunane $P$, Chaipornsupaisan W, Vos T: A survey of severity, quality of life and current treatment patterns in people with schizophrenia in Thailand 2008 Bangkok: SPICE project; 2008.

21. Gold MR, Siegal JE, Russell LB, Weinstein MC: Cost-effectiveness in health and medicine New York: Oxford University Press, Inc.; 1996.

22. Magnus A, Carr V, Mihalopoulos C, Carter R, Vos T: Assessing costeffectiveness of drug interventions for schizophrenia. Australian and New Zealand Journal of Psychiatry 2005, 39:44-54.

23. Deeks JJ, Altman DG, Bradburn MJ: Statistical methods for examining heterogeneity and combining results from several studies in metaanalysis. In Systematic Reviews in Health Care: Meta-Analysis in Context.. 2 edition. Edited by: Egger M, Smith GD, Altman D. London: BMJ Publishing Group; 2001:211-228.

24. Haby MM, Carter R, Mihalopoulos C, Magnus A, Sanderson K, Andrews G, Vos T: Assessing cost-effectiveness - mental health: introduction to the study and methods. Australian and New Zealand Journal of Psychiatry 2004, 38:569-578.

25. Duggan LFM, Rathbone J, Dardennes R, El-Dosoky A, Indran S: Olanzapine for schizophrenia. Cochrane Database of Systematic Reviews 2005

26. Essali AA-HHN, Li C, Rathbone J: Clozapine versus typical neuroleptic medication for schizophrenia. Cochrane Database of Systematic Reviews 2009.

27. Hunter RHJC, Kennedy E, Gilbody SM, Song F: Risperidone versus typical antipsychotic medication for schizophrenia. Cochrane Database of Systematic Reviews 2003.

28. Irving CBAC, Lawrie S: Haloperidol versus placebo for schizophrenia. Cochrane Database of Systematic Reviews 2006.

29. Pekkala E, Merinder L: Psychoeducation for Schizophrenia. Cochrane Database of Systematic Review John Wiley \& Sons, Ltd; 2002

30. Pharoah F, Marit J, Rathbone J, Wong W: Family intervention for schizophrenia. Cochrane Database of Systematic Reviews John Wilet \& Son, Ltd; 2006.

31. Phanthunane $P$, Vos $T$, Whiteford $H$, Bertram M: Health outcomes of schizophrenia in Thailand: Health care provider and patient perspectives. Asian Journal of Psychiatry 2010, 3:200-205.

32. Stouthard ME, Essink-Bot M-L, Bonsel GJ, Barendregt JJ, Kramer PGN, Water HPAvd, Schepers LG, Maas PJv: Disability weights for diseases in the 
Netherland Rotterdam: Department of Public Health, Erasmus University Rotterdam; 1997.

33. Harris EC, Barraclough B: Suicide as an outcome for mental disorders. A meta-analysis. The British Journal of Psychiatry 1997, 170:205-228.

34. Munro J, O'Sullivan D, Andrews C, Arana A, Mortimer A, Kerwin R: Active monitoring of 12,760 clozapine recipients in the UK and Ireland. Beyond pharmacovigilance. 1999, 175(576-580):576-580.

35. Harris EC, Barraclough B: Excess mortality of mental disorder. 1998, 173(11-53):11-53.

36. Lacro JPDL, Dolder CR, et al: Prevalence of and risk factors for medication nonadherence in patients with schizophrenia: a comprehensive review of recent literature. J Clin Psychiatry 2002, 63:892-909.

37. Prukkanone B, Vos T, Burgess P, Chaiyakunapruk N, Bertram M: Adherence to antidepressant therapy for major depressive patients in a psychiatric hospital in Thailand. BMC Psychiatry 2010, 10:64.

38. Matthew JB, Paul AN, Emmeline L: Antipsychotic Medication Adherence in Schizophrenia. The Psychiatric clinics of North America 2007, 30:437.

39. Valenstein M, Blow F, Copeland L, McCarthy J, Zeber J, Gillon L, Bingham C, Stavenger T: Poor Antipsychotic Adherence Among Patients With Schizophrenia: Medication and Patient Factors. Schizophrenia Bulletin 2004, 30:255.

40. Grunder G, Hippius H, Carlsson A: The 'atypicality' of antipsychotics: a concept re-examined and re-defined. Nat Rev Drug Discov 2009, 8:197-202.

41. Leucht S, Wahlbeck K, Hamann J, Kissling W: New generation antipsychotics versus low-potency conventional antipsychotics: a systematic review and meta-analysis. Lancet 2003, 361:1581-1589.

42. Adams CE, Awad G, Rathbone J, Thornley B: Chlorpromazine versus placebo for schizophrenia. Cochrane Database Syst Rev 2007.

43. Cheng L-Y, Chan S: Psychoeducation Program for Chinese Family Carers of Members With Schizophrenia. West J Nurs Res 2005, 27:583-599.

44. Matichon: The happiness of people with mental disorder-cheaper medications. Matichononline; 2009

45. Vos T, Haby MM, Magnus A, Mihalopoulos C, Andrews G, Carter R: Assessing cost-effectiveness in mental health: helping policy-makers prioritize and plan health services. Australian and New Zealand Journal of Psychiatry 2005, 39:701-712.

46. Tandon R, Targum SD, Nasrallah HA, Ross R: Strategies for maximizing clinical effectiveness in the treatment of schizophrenia. Journal of Psychiatric Practice 2006, 12:348-363.

47. Chantarasak S: Study of safety and outcomes of clozapine for treatmetn of schizophrenia at Sruthunya hospital. Journal of Mental Health of Thailand 2003, 9:82.

48. Kelvin MT, Fung HWHT, Patrick W Corrigan: Self-stigma of people with schizophrenia as predictor of their adherence to psychosocial treatment. Psychiatric Rehabilitation Journal 2008, 32:95-104.

49. Heeg BMS, Damen J, Buskens E, Caleo S, Frank de C, van Hout BA: Modelling Approaches: The Case of Schizophrenia. PharmacoEconomics 2008, 26:633-648.

50. Voruganti L, Cortese L, Owyeumi L, Kotteda V, Cernovsky Z, Zirul S, Awad A: Switching from conventional to novel antipsychotic drugs: results of a prospective naturalistic study. Schizophr Res 2002, 57:201.

51. Rosenheck RA, Davis S, Covell N, Essock S, Swartz M, Stroup S, McEvoy J, Lieberman J: Does switching to a new antipsychotic improve outcomes?: Data from the CATIE trial. Schizophr Res 2009, 107:22-29.

52. Obradovic M, Mrhar A, Kos M: Cost-effectiveness of antipsychotics for outpatients with chronic schizophrenia. Int J Clin Pract 2007, 61:1979-1988

53. Lindner LM, Marasciulo AC, Farias MR, Grohs GEM: Economic evaluation of antipsychotic drugs for schizophrenia treatment within the Brazilian healthcare system. Rev Saúde Pública 2009, 43:62-69.

54. Cooper D, Moisan J, Abdous B, Grégoire JP: A population-based costeffectiveness analysis of olanzapine and risperidone among ambulatory patients with schizophrenia. Can J Clin Pharmacol 2008, 15:385-397.

55. Chisholm D, Gureje O, Saldivia S, Villalón Calderón M, Wickremasinghe R, Mendis N, Ayuso-Mateos J-L, Saxena S: Schizophrenia treatment in the developing world: an interregional and multinational cost-effectiveness analysis. WHO bulletin 2008, 86:542-551.

56. Allison DB, Mentore $\mathrm{JL}$, Heo M, Chandler LP, Cappelleri JC, Infante MC, Weiden PJ: Antipsychotic-Induced Weight Gain: A Comprehensive Research Synthesis. Am J Psychiatry 1999, 156:1686-1696.
57. Jablensky A, McGrath J, Herrman H, Castle D, Gureje O, Evans M, Carr V Morgan V, Korten A, Harvey C: Psychotic disorders in urban areas: an overview of the Study on Low Prevalence Disorders. Australian and New Zealand Journal of Psychiatry 2000, 34:221.

58. Savilla K, Kettler L, Galletly C: Relationships between cognitive deficits, symptoms and quality of life in schizophrenia. Australian and New Zealand Journal of Psychiatry 2008, 42:496-504.

59. Narvaez JM, Twamley EW, McKibbin CL, Heaton RK, Patterson TL: Subjective and objective quality of life in schizophrenia. Schizophr Res 2008, 98:201-208.

60. Sitzer DITEW, Patterson TL, Jeste DV: Multivariate predictors of social skills performance in middle-aged and older out-patients with schizophrenia spectrum disorders. Psychological medicine 2008, 38:755-763.

61. Tiihonen J, Lönnqvist J, Wahlbeck K, Klaukka T, Niskanen L, Tanskanen A, Haukka J: 11-year follow-up of mortality in patients with schizophrenia: a population-based cohort study (FIN11 study). The Lancet 2009, 374:620-627.

doi:10.1186/1478-7547-9-6

Cite this article as: Phanthunane et al:: Cost-effectiveness of pharmacological and psychosocial interventions for schizophrenia. Cost Effectiveness and Resource Allocation 2011 9:6.

\section{Submit your next manuscript to BioMed Central and take full advantage of:}

- Convenient online submission

- Thorough peer review

- No space constraints or color figure charges

- Immediate publication on acceptance

- Inclusion in PubMed, CAS, Scopus and Google Scholar

- Research which is freely available for redistribution

Submit your manuscript at www.biomedcentral.com/submit
Biomed Central 